\title{
Hydrogen as energy-storage-medium and fuel
}

\section{A strong partner of renewable energies}

\author{
Johannes Töpler ${ }^{*}$ \\ German Hydrogen and Fuel Cell Association (DWV), Berlin, Germany
}

\begin{abstract}
This contribution addresses the future energy situation with the expected reduction of fossil primary energy supply and increasing market segments by renewable energies within the next decades. The potential of renewable energies to cover the energy demand is described as well as the necessity of energy storage systems (especially hydrogen) to compensate the fluctuations of primary energy sources. Furthermore the increasing use of renewable vehicle fuels is investigated with special focus on hydrogen in short and long-term considerations. As a result the paper will show an energy supply gap between decreasing fossil energies and increasing renewable energies which can only be bridged by a more efficient general use of energy. Hydrogen will be proven as best synthetic fuel by "well-to-wheel analysis" both with respect to energy efficiency, to environmental analysis as well as to customer satisfaction.
\end{abstract}

\section{Introduction}

Germany is the only country of the earth, in which the energy transition from fossil fuels to renewable energies is decided.

The main reasons for this are mainly:

- The damage of climate due to $\mathrm{CO}_{2}$-emissions is obvious right now and will increase further on (in spite of Kyotoprotocol).

- The availability of fossil primary energies is limited to approximately 50-80 years (with respect to probable annual growing rates even less!).

- Fossil energy carriers are raw materials for organic chemistry $\rightarrow$ to valuable for burning.

- The energy demand worldwide will increase (especially by the developing countries) and will aggravate the situation.

- The introduction of a new energy-system will need in principal about 50 years for the first $10 \%$ of market penetration (Marcetti, 1980).

The consequence should be: it is very high time to introduce $\mathrm{CO}_{2}$-free renewable energies (if necessary via primary energies with less $\mathrm{CO}_{2}$ ), with hydrogen as secondary energy carrier which can be stored, transported and used in manifold applications.

\section{Future energy supply}

The availability of fossil primary energies and nuclear energy is shown in Figure 1.

\footnotetext{
* e-mail: toepler@h2de.de
}

The aggregate supply of fossil and nuclear energy is expected to peak by around 2015 .

After the peaking of the oil supply ( today) [1], the global supply of natural gas, coal [2] and nuclear fuel [3] is expected to reach a combined maximum by around $2020-$ at the latest. This will have significant impacts on the total energy supply. With peak oil we are entering into a transition phase towards a post-fossil energy area.

But the velocity for this energy change is not given by the reduced resources of fossil fuels, but by the efforts to avoid a climate change by $\mathrm{CO}_{2}$-emissions.

The position of the International Energy Agency is: "We have to leave oil, before oil will leave us" (Fatih Birol, 2008).

The limitation in availability of fossil energy resources as well as the threat of climate change to biosphere has led to the formulation of political goals with regard to security of energy supply and especially reduction of greenhouse gas emissions. All the underlying issues can be addressed in an efficient and sustainable way by energy conservation, by the increased use of renewable energy sources and by the use of hydrogen and fuel cells.

In the long term, renewable energies will be able to provide more energy than all fossil and nuclear fuels will have been able to supply at their aggregate peak. On a global level, solar energy and wind power can become the major pillars of our energy system (Fig. 2).

The transition from fossil fuels to renewable energies is a transition from primary energy fuels (i.e. crude oil, natural gas, coal) to electricity (e.g. from photovoltaics, solar thermal power-plants, wind or hydropower). This will offer new options and opportunities but also new challenges for the future energy system. 


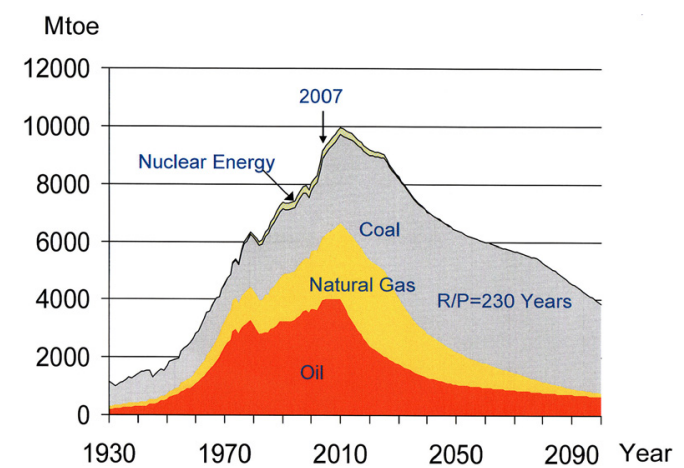

Fig. 1. Contribution of fossil and nuclear energy sources. Source: LBST, 2005.

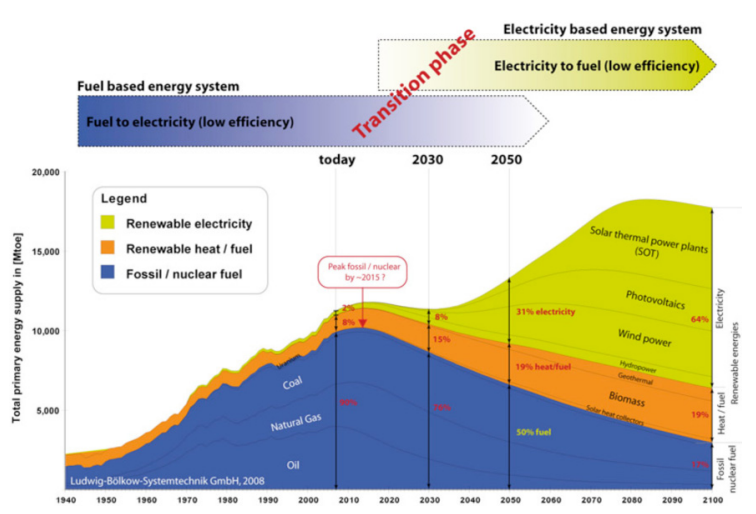

Fig. 2. Future primary energy supply. Source: LBST, 2005.

To a large extent, the transport sector will be electrified. In the last years, road vehicles have started to switch to renewable electricity as a "primary energy source". Hydrogen will become a very essential partner for the future transport sector. As electricity from wind and solar energy is difficult to store, hydrogen will serve as electricity storage and as a transport fuel for future vehicles. Vehicles with longer operating ranges, higher payloads and fast refuelling capabilities very likely will have to be hydrogen fuel cell vehicles in the foreseeable future.

\section{Technical potential of renewable electricity - worldwide}

Renewable electricity could become the most important energy of the world. Figure 3 summarises the technical potential for the production of renewable electricity from photovoltaics (PV), solar thermal power plants, wind and hydropower by world regions. Today's global electricity use lies in the order of $18,000 \mathrm{TWh}$ per year.

\subsection{Renewable electricity generation}

The share of renewable electricity is expected to increase significantly since the largest potentials for renewable energies in Europe and Germany are identified as wind, hydropower, solar and geothermal electricity. In 2007, the German Federal Ministry for the Environment, Nature

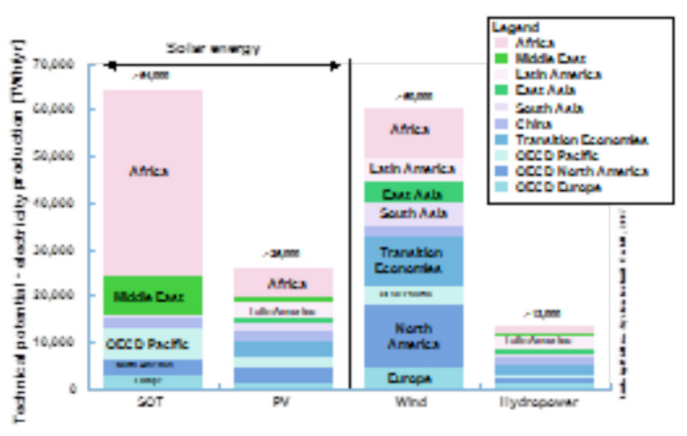

Fig. 3. Potential of renewable electricity. Source: LBST, 2005.

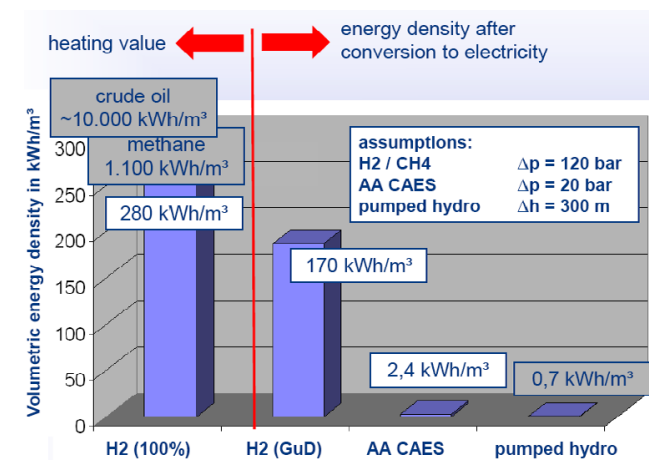

Fig. 4. Energy densities for different energy storage systems. Source: KBB-UT.

Conservation and Nuclear Safety has published the Guiding Study 2007 "Development Strategy Renewable Energies" [4]. This study predicts that the electricity production from renewable resources will increase from $74 \mathrm{TWh}$ in 2006 to $156 \mathrm{TWh}$ in 2020 . With regard to the current and presumably also the future electricity production this represents more than $25 \%$ of the overall production. This scenario also reflects the already enacted and binding goals of the European Union.

\subsection{Renewable electricity storage}

With increasing share of renewable electricity our future energy system will require large scale storage systems for electricity. Today, pumped hydro power stations are the only widely used means to store electricity at industrial scale. But the potential for further extension and new installations is very limited. The only technology at present knowledge which has the potential for single storage systems in the $100 \mathrm{GWh}$ range is the storage of hydrogen (with high energy storage densities) in underground salt caverns (Fig. 4).

\subsubsection{Costs for electricity storage}

Pumped hydropower storage systems or (adiabatic) compressed air systems have high efficiencies, because the potential energy of different levels or compression can directly be converted to electricity. The efficiency of storing electricity by hydrogen is lower $(\sim 50 \%)$ due to the 


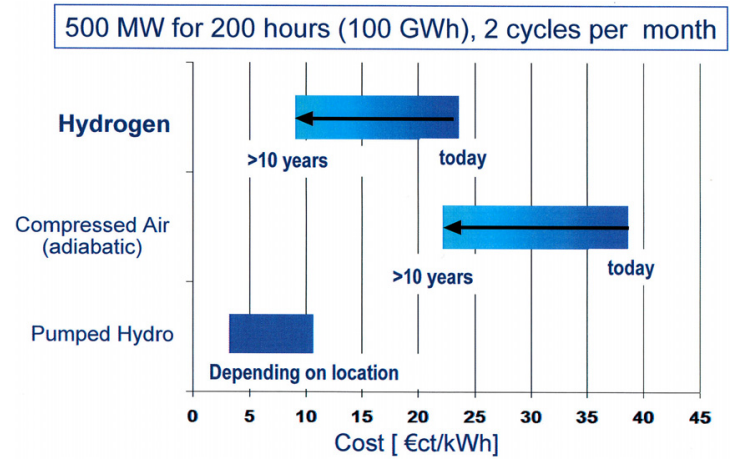

Fig. 5. Storage costs for "Storage by weeks". Source: Study of VDE, 2009.

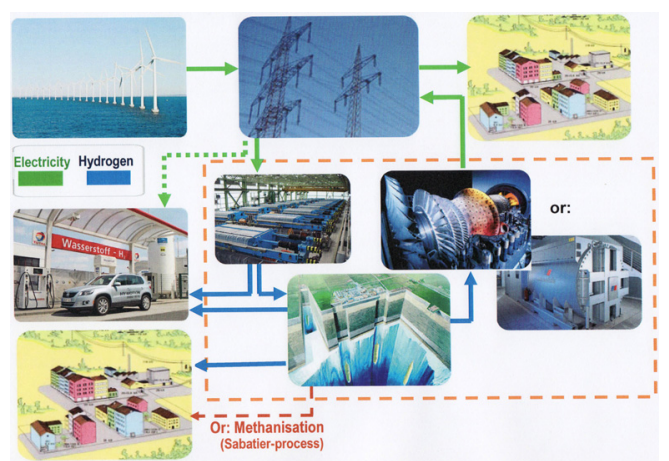

Fig. 6. Ways of hydrogen storage and utilization.

additional conversions by electrolysis and fuel cells (or turbines), but the high energy density enables hydrogen to store huge amounts of energy. Figure 5 indicates the costs for "storage by weeks", which is necessary for long-term fluctuations of renewable primary energies. Hydrogen has the best opportunities with respect to the triangle of energy density, efficiency and reasonable price. By this way, hydrogen makes the renewable primary energies ready for basic power supply.

\section{Hydrogen as transport fuel}

In addition to the necessity to use hydrogen for storage and load compensation a further pathway for the utilisation of sustainably produced hydrogen will be its use in the transportation sector (Fig. 6). The current discussions on $\mathrm{CO}_{2}$ reduction and the availability of fossil fuels show, that car industry is speeding up with their efforts to develop hydrogen powered vehicles and that first vehicle sales can be expected for 2015 followed by a broad market entry from 2017 corresponding to newest announcements of different car manufacturing companies.

Furthermore, it can be observed that hydrogen propulsion in passenger cars is as twice as efficient enduse technology than today's direct injection engines and thus displaces conventional fuels and power trains more efficiently than using hydrogen in stationary conversion units (combined cycle power plants or fuel cell systems) where it competes for the time being with almost as efficient natural gas-based end-use technologies.

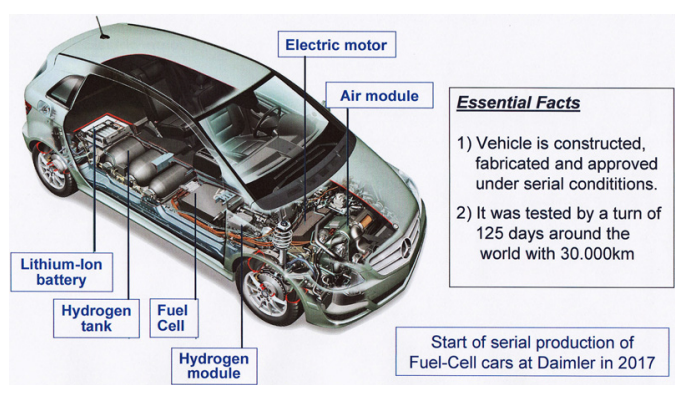

Fig. 7. B-Class of Daimler with fuel cells.

Finally it should be mentioned, that these topics - largescale storage of hydrogen, utilisation of hydrogen as a storage medium for electrical energy and the utilisation of surplus energy in the transportation sector - only played a sub-ordinate role in $\mathrm{R} \& \mathrm{D}$ activities in the past. Based on the above-mentioned possibilities this technology can provide, it is urgently needed that both industry and politics attend to this topic and provide the required resources allowing to find suitable answers to the pending changes in the energy landscape.

One example for the construction and design of a fuel cell vehicle is given in Figure 7 by a B-Class car from Daimler. This car was fabricated under serial conditions with corresponding approvals. A tour with $30,000 \mathrm{~km}$ around the world in 2011 demonstrated the applicability of this technology for general use.

Other car manufacturers in Europe, Asia and US are going similar ways, sometimes in bilateral cooperation. A start for the market penetration is announced within this decade.

Another actual mobile application of hydrogen is the use in urban busses. Many cities (i.e. Hamburg, Cologne, Berlin, London .... ) are using hydrogen-hybrid busses since several years. It is planed to extend the numbers of these busses significantly.

New technical concepts with fuel cells as range extenders for trolley busses are just in preparation, for example in Riga.

\subsection{Special aspects of fuel-cell-vehicles with respect to alternatives}

Very often electric vehicles with battery storage systems are considered as competitors to electric vehicles powered by hydrogen via fuel cells. But in reality both types of electric vehicles complement one another. With respect to the market segments this complementation was investigated in a "Coalition Study" as a EU-project (see Fig. 8).

In the segment of small vehicles and short annual ranges battery vehicles are to be preferred due to the high efficiency of battery-storage systems. In the case of bigger vehicles and longer ranges more energy is needed on board of the vehicle, so that batteries are too heavy and hydrogen is needed, even if a smaller efficiency due to the additional energy conversion of the hydrogen path is to be accepted.

In general a fuel cell car is hybridized by an additional battery (see Fig. 9). The main reason is the recovery of braking energy by using the electric engine as generator. 


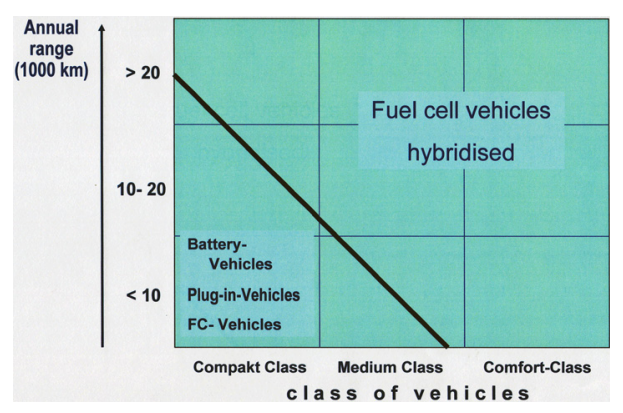

Fig. 8. Market segments of battery- and fuel-cell-vehicles. Source: Coalition study [5].

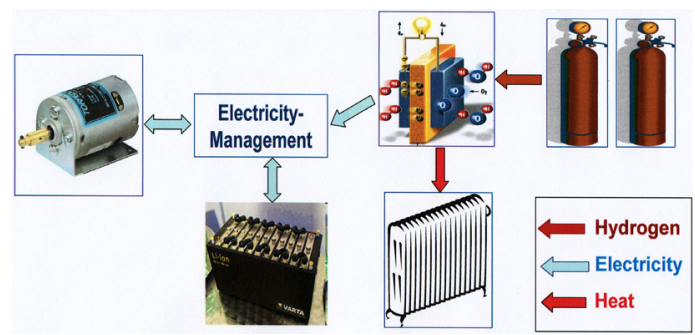

Fig. 9. Energy management of a hybridized battery/fuel-cell car.

The second reason is the extra power supply in the case of peak load and the third reason is use of waste heat of fuel cell for preheating the car at low temperatures. For this purpose a fuel cell can be started some time before departure. The electricity is used to fill the battery and the waste heat is used for preheating the car. When driving the electricity is withdrawn from battery and fuel cell, so that enough heat is available for the car and the battery is empty again at the arrival, so that the process car start again for the next ride. By this way heating and preheating of the car is available without loss of range.

In Figure 2, it was just shown that in future significant amounts of energy from biomass will be available (preferably from biomass of 1st generation without competition to food-production).

For the use in mobility this biomass will mainly be converted to bio-ethanol or bio-diesel.

Both liquid fuels will be used in internal combustion engines with typical Carnot-like efficiency curves in depending on the load of the engine.

Increasing combustion temperatures are related to increasing efficiencies and increasing power densities (see Fig. 10).

The maximum of efficiency for a fuel cell vehicle is in the low load sector - in the typical operation mode of passenger cars, urban busses and small delivery vans.

As a consequence fuel cell systems are mainly suitable for these vehicles, whereas internal combustions engines with biofuels have highest efficiencies which are mainly operated with high load - heavy trucks, motor-coaches, airplanes, big ships, etc.

Both fuel types - liquid from biomass and hydrogen from renewable electricity - are needed to reduce $\mathrm{CO}_{2^{-}}$ emissions in mobility, but preferably each one for its best efficiency-range.

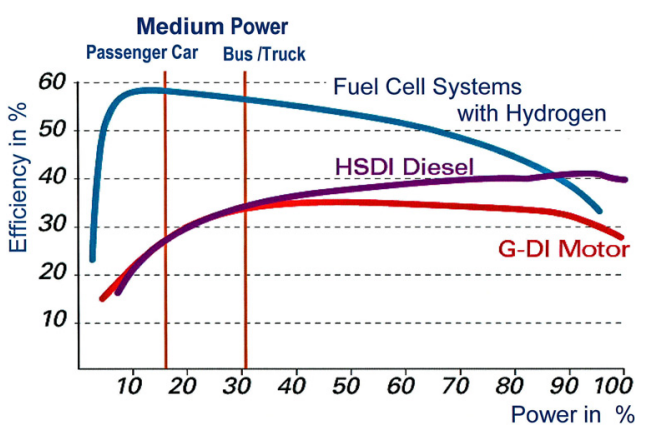

Fig. 10. Comparison of efficiencies for a fuel cell system and internal combustion engine. Source: IBZ.

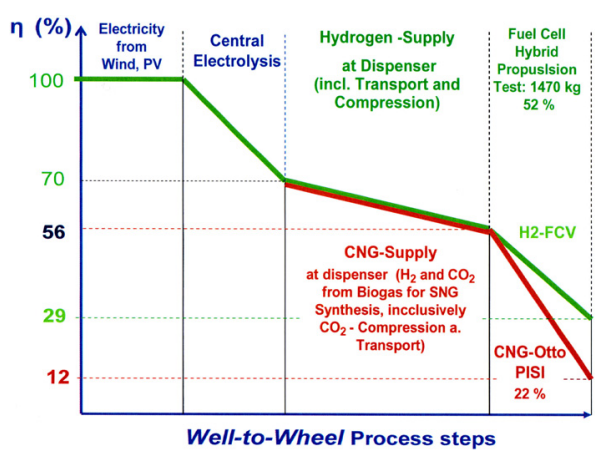

Fig. 11. W-t-W with renewable electricity: $\mathrm{H}_{2}$ or $\mathrm{CNG}$ for mobile application of passenger cars in NEDC. Original source of figures: Kreyenberg [6].

In Figure 6, it was just indicated, that after hydrogen production by electrolysis a further conversion by Sabatier process to methane is possible. This conversion to "synthetic natural gas" (SNG) can be handled as compressed natural gas (CNG), using the existing infrastructure.

By this way the use of SNG as fuel in vehicles is also possible - in internal combustion engines. Even if the efficiencies of ICE's are significantly lower, there is the argument, that the initial energy as "surplus of renewable electricity" is free of cost.

In Figure 11, it is shown the efficiency chain from renewable electricity to the wheel of a passenger car for the energy path of hydrogen production, transport and use in fuel cells in comparison to the energy path via CNG and ICE.

It is remarkable, that the energy loss by Sabatierprocess for methanisation is nearly the same as the energy demand for transport and compression of the hydrogen path. The main difference of efficiency is the end-use in the car for the normalized New European Driving Cycle (NEDC) by internal combustion engine $(22 \%)$ and fuel cell $(52 \%)$. So, in summery the overall efficiency for the SNG-ICE-path is $12 \%$ in comparison to $29 \%$ for the $\mathrm{H}_{2}$-FCpath.

From the first point of view this seems not to be very severe, because the initial energy as "surplus" of fluctuating renewable energy is free of cost.

But a more rigorous view is given by an efficiency consideration starting from a normalized numerical value of 1 for the used end-energy at the wheel (Fig. 12). 


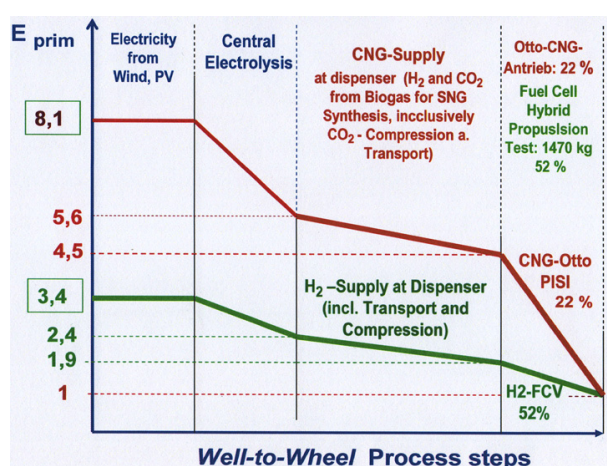

Fig. 12. W-t-W with renewable electricity: $\mathrm{H}_{2}$ or CNG for mobile application of passenger cars in NEDC (normalized to 1 for final energy at wheel).

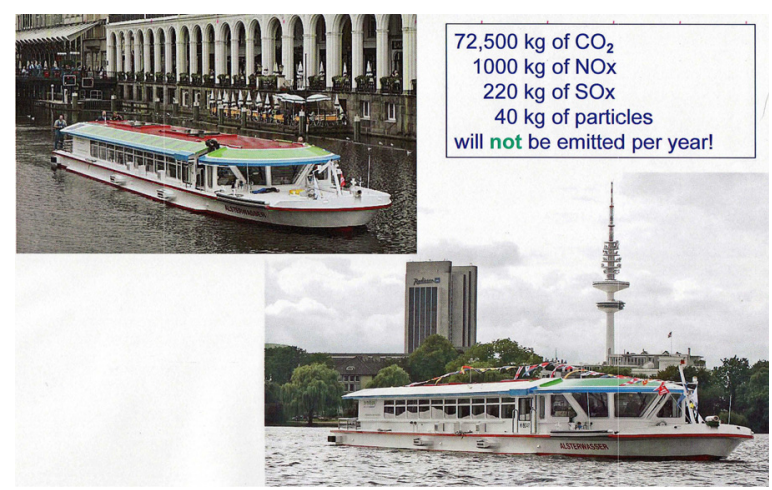

Fig. 13. "Zem-Ship" with hydrogen-fuel cell-propulsion in the harbor of Hamburg.

By this consideration it becomes clear, that for the same final energy at the wheel and under the same meteorological conditions the primary energy for the SNG-ICE-path $(8,1)$ is bigger by a of 2,4 than for the $\mathrm{H}_{2}$-FC-path. This means the size of primary energy plants (incl. the corresponding investment cost) has to be higher by the same factor. Therefore, the efficiency of fuel cells has highest importance for a decision of energy paths.

A lot of more concepts for the mobile application of $\mathrm{H}_{2}$ / FC-systems are considered at present:

- for ships and airplanes as auxiliary power unit for big systems or as propulsion for small ones,

- for materials handling systems,

- for small propulsion systems (bicycles, wheel chairs).

For more details of these new mobile applications of fuel cell systems pleas see [7].

One example for a just existing fuel cell propulsion in a ship is shown in Figure 13. The "Zero-Emission-Ship" (ZEM-Ship) is operated in the harbor of Hamburg for round trips.

An example for the $\mathrm{H}_{2} / \mathrm{FC}$-application in airplanes is shown in Figure 14. An APU in an Airbus is used for power generation with different additional benefits like battery

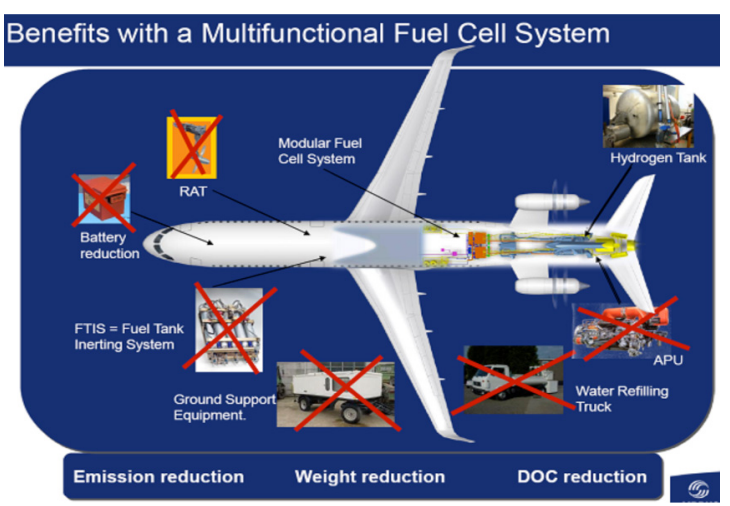

Fig. 14. Airbus with APU with hydrogen and fuel cell.

reduction, water production, use of $\mathrm{O}_{2}$-degraded air for tank-inerting system, ground support, etc. The system is still in development.

In a summary of basic statements it can be recapitulated:

- Hydrogen makes renewable primary energies ready for basic power supply,

- Hydrogen makes the energy transition affordable (due to its energy-storing capability and a lot of further applications),

- Hydrogen introduces renewable energies into mobility,

- Hydrogen enables electric vehicles to reach long distances,

- Hydrogen makes mobility $\mathrm{CO}_{2}$-free.

Hydrogen and fuel cells are strong partners of renewable primary energies and are essential elements for the energy transition.

\section{References}

1. Energy Watch Group, Crude Oil - The Supply Outlook, Oct. 2007, EWG-Series No 3/2007 (2007): http://www.energy watchgroup.org

2. Energy Watch Group, Coal: Resources and Future Prod., Mar. 2007, EWG-Series No 1/2007 (2007)

3. Energy Watch Group, Uranium Resources and Nuclear Energy, Dec. 2006, EWG-Series No 1/2006 (2006)

4. J. Nitsch, Lead Study 2007 (DLR Institute for Technical Thermodynamics, 2007)

5. http://chic-project.eu/newsevents/news/eu-policy-news/ mckinsey-european-hydrogen-infrastructure-\%E2\%80\%99jus tified-and-doable\%E2\%80\%99

6. D. Kreyenberg/J. Wind, Daimler, Dt. H2-Congress Berlin: www.OPTIRESOURCE.com (2012)

7. J. Töpler, J. Lehman (eds.), Wasserstoff und Brennstoffzellen - Technologien und Marktperspektiven (Springer-Verlag, Heidelberg, 2013). ISBN 978-3-642-37414-2. English-Version: Hydrogen and Fuel Cell - Technologies and Market Perspectives, in preparation, to be published in Oct. 2015. ISBN 978-3662-44971-4 